\title{
DA EDUCAÇÃO INFANTIL E A EXPERIÊNCIA DE REGGIO EMILIA
}

\author{
Tatiana Costa Martins \\ Pedagoga com ênfase em Orientação Educacional, pelo Centro Universitário Luterano de Palmas \\ CEULP/ULBRA - Especialista em Gestão Escolar pela Universidade Federal do Tocantins - \\ Pós-graduanda em Psicopedagogia pela Universidade Católica Dom Bosco e em Formação de Gestores \\ Educacionais pela Unyleya - Orientadora Educacional na Rede Municipal de Ensino. \\ Professora Pesquisadora UAB/UNITINS. \\ \taticmartins@gmail.com
}

\begin{abstract}
Resumo:
A Educação Infantil vista à luz de teorias progressistas da Pedagogia como etapa primordial para o desenvolvimento dos aspectos psicomotores que balizam todos os demais processos de construção do conhecimento, precisa ser compreendida pela sociedade como fundamental para a formação da personalidade em âmbito de constituição do sujeito histórico e social. À escola infunde-se este papel mediador de entrelaçar as famílias aos conhecimentos pedagógicos que norteiam as ações direcionadas a esta etapa da escolarização infantil. $\mathrm{O}$ reconhecimento da infância como fase de elevado potencial criativo e intelectual que se associa à construção dos valores individuais e coletivos que acompanharão o indivíduo por toda a vida adulta são elementos de grande importância na construção de novos posicionamentos educacionais. A parceria entre escola e família, que se inicia nas experiências educativas desde a creche e a Educação Infantil, por vezes perde-se em lacunas imperceptíveis como o acompanhamento e a orientação profissional sobre o ingresso da criança no Ensino Fundamental, inseguranças e ansiedades das crianças e seus familiares. A experiência de Reggio Emilia, expressa na Pedagogia da Escuta, vem ao encontro do desenvolvimento da autonomia, criticidade e o fortalecimento da parceria entre escola e família. Uma reflexão oportuna a todos os educadores que compreendem a Educação enquanto processo transformador.
\end{abstract}

Palavras-chave: Educação Infantil; Projetos Educativos; Pedagogia da Escuta.

\section{THE EARLY CHILDHOOD EDUCATION AND REGGIO EMILIA EXPERIENCE}

\begin{abstract}
:
The Early Childhood Education seen in the light of progressive theories of pedagogy as a key step for the development of psychomotor aspects that guide all other knowledge-building processes, must be understood by society as fundamental to the formation of personality in the context of establishment of the historical subject and social. To school instills up this mediating role of interweaving families to teaching skills that guide the actions directed at this stage of children's schooling. The recognition of childhood as a stage of high creative and intellectual potential that is associated with the construction of individual and collective values that accompany the individual throughout adult life is great important element in building new educational placements. The partnership between school and family, beginning
\end{abstract}


in educational experiences from kindergarten and early childhood education sometimes get lost in noticeable gaps as monitoring and professional guidance on the admission of children in elementary school, insecurities and anxieties of children and their families. The experience of Reggio Emilia, expressed in the Pedagogy of Listening, meets the development of autonomy, critical and strengthening the partnership between school and family. A timely reflection to all educators who understand education as a transforming process.

Keywords: Early Childhood Education; Educational Projects; Pedagogy of Listening.

\section{DE LA EDUCACIÓN DE LA PRIMERA INFANCIA Y LA EXPERIENCIA DE REGGIO EMILIA}

\section{Resumen:}

La Educación de la Primera Infancia visto a la luz de las teorías progresistas de pedagogía como un paso clave para el desarrollo de los aspectos psicomotores que guían el resto de los procesos de construcción del conocimiento, debe ser entendida por la sociedad como fundamental para la formación de la personalidad en el contexto del establecimiento del sujeto histórico y social. Ir a la escuela inculca este papel mediador de entretejer las familias a las habilidades de enseñanza que guían las acciones dirigidas en esta etapa de la escolarización de los niños. El reconocimiento de la infancia como una etapa de alto potencial creativo e intelectual que se asocia con la construcción de los valores individuales y colectivos que acompañan al individuo durante toda la vida adulta es un gran elemento importante en la construcción de nuevas colocaciones educativas. La asociación entre la escuela y la familia, a partir de las experiencias educativas desde preescolar y la educación de la primera infancia a veces se pierden en las lagunas notables como el seguimiento y la orientación profesional, sobre la admisión de los niños en la escuela primaria, inseguridades y ansiedades de los niños y sus familias. La experiencia de Reggio Emilia, expresada en la Pedagogía de la Escucha, se encuentra con el desarrollo de la autonomía, crítica y el fortalecimiento de la colaboración entre la escuela y la familia. Una reflexión oportuna a todos los educadores que entienden la educación como un proceso de transformación.

Palabras clave: Educación Infantil; Proyectos Educativos; Pedagogía de la Escucha.

\section{INTRODUÇÃO}

Uma concepção pedagógica que vá além de antigas dicotomias, entre elas, função da família/função da escola, prazer/aprender, ensino/aprendizagem, disciplina/concentração, agregará valor às práticas educacionais que se efetivam dentro e fora da escola. Por vezes, os educadores questionam a postura das famílias sem a reflexão inicial de que uma visão pedagógica sobre a Educação necessita ser construída em parceria com a escola e através da efetiva intervenção desta.

O ingresso da criança na Instituição de Ensino, na creche ou na Educação Infantil, sendo previsto como obrigatório, com carga horária específica e a partir dos quatro anos 
através da Lei $n^{\circ} 12.796 / 2013$, é cercado por particularidades que chamam atenção para processos importantes, entre os quais, a adaptação à rotina, a segurança quanto ao ambiente e às pessoas, o desenvolvimento da autoestima e o posicionamento no grupo de convívio. Vários são os vieses pelos quais pais e educadores necessitam dar o devido suporte à criança, mediando suas descobertas e encorajando conquistas diárias, subsidiando o protagonismo nas situações de aprendizagem.

Os apontamentos iniciais denotam a importância de um olhar atento para com o desenvolvimento infantil mediado pela escola, e evidenciam o caráter deste trabalho que se propõe a contribuir com educadores e público em geral que busquem leituras com referenciais teóricos que colocam em xeque a tradicional visão da criança enquanto adulto em miniatura, valorizando assim cada etapa do desenvolvimento, sentimentos, pensamentos e expressões.

O caráter científico se expressa na condição de subsídio para outras pesquisas relacionadas à temática, contemplando principalmente profissionais da educação. O estudo, que em âmbito metodológico centra-se na pesquisa bibliográfica, aborda concepções teóricas sobre a Educação Infantil a partir de relevantes autores que propõem parcerias entre família e escola na primeira fase da Educação Básica, com inferências à necessidade de acompanhamento pedagógico e orientação quanto ao ingresso da criança no Ensino Fundamental. Entre as bibliografias que compõem este aporte reflexivo destaca-se a proposta da Pedagogia da Escuta, cunhada pelo educador Loris Malaguzzi (1920 - 1994), que essencialmente valoriza as diversas linguagens das crianças, de forma que os projetos pedagógicos partam do interesse expresso pelas mesmas, com a mediação dos educadores.

De caráter essencialmente qualitativo, o estudo bibliográfico e o relato de vivências em Reggio Emilia, na Itália, se voltam para o fortalecimento dos saberes profissionais dos educadores, para que através da busca pela parceria com as famílias e o reconhecimento dos processos biopsicossociais da infância, estabeleçam-se vínculos significativos e fecundos, de maneira que educadores construam junto aos adultos da comunidade escolar, principalmente familiares, uma visão de valorização para com a Educação como um todo. 


\section{METODOLOGIA}

A pesquisa bibliográfica associa-se ao relato de experiência vivenciada na cidade de Reggio Emilia, localizada ao norte da Itália, no ano de 2014. Possui a finalidade de apresentar um significativo aporte teórico que forneça subsídios aos leitores para que reflitam de forma crítica acerca da temática sobre a valorização da Educação Infantil e a devida atenção para com o ingresso no Ensino Fundamental.

Seguiu os critérios apresentados por Minayo (1992) quanto à importância de a pesquisa qualitativa preconizar uma fase exploratória, definindo-se assim o objeto da pesquisa e o diálogo reflexivo junto às teorias. Ainda segundo a autora, a pesquisa é a coesão dos dados teóricos e práticos.

[...] é a atividade básica da Ciência na sua indagação e construção da realidade. É a pesquisa que alimenta a atividade de ensino e a atualiza frente à realidade do mundo. Portanto, embora seja uma prática teórica, a pesquisa vincula pensamento e ação. Ou seja, nada pode ser intelectualmente um problema, se não tiver sido, em primeiro lugar, um problema da vida prática. (MINAYO, 1992, p. 17).

Essa proposição dialética corrobora com Lakatos (2003) quando afirma que o ponto de partida é a tese, que se expressa em uma proposição positiva, sob a qual há uma negação ou contradição, manifestando-se na antítese, que por sua vez gera uma terceira proposição ou síntese. Assim, o leitor ativo, nesta proposta de revisão bibliográfica e reflexiva no confronto entre teoria e prática, encontra apontamentos importantes para construir conceitos e ressignificar posicionamentos frente à Educação enquanto processo formativo.

\section{RESULTADOS}

O Brasil possui dimensões continentais e a diversidade marca cada região. Nas escolas este fenômeno da heterogeneidade não é diferente. Marcadamente plurais, as salas de aula se contrastam com anseios, desejos e necessidades de estudantes, professores e toda comunidade escolar. Na Educação Infantil tais demandas são reais e a compreensão sobre a importância desta etapa da escolarização auxilia na formação integral à qual se propõem as ações educativas dentro das especificidades de cada faixa etária.

Os relatos de países desenvolvidos acerca da Educação Infantil, tendo como ícone mundial a experiência educativa da cidade de Reggio Emilia, na Itália, apontam para estratégias pedagógicas que não subestimem o potencial infantil, e que desafiem e 
diversifiquem as práticas, priorizando o desenvolvimento da autonomia e criatividade em detrimento ao currículo rígido que, porventura, organize conteúdos estáticos, pautando-se em perspectivas Sócio-construtivistas.

No Brasil, o RCNEI - Referencial Curricular Nacional da Educação Infantil (1998) apresenta abordagens em Eixos de Aprendizagem, sendo Identidade e Autonomia, Movimento, Música, Artes Visuais, Linguagem Oral e Escrita, Natureza e Sociedade, e Matemática, também com uma perspectiva Sócio-interacionista, subsidiando o desenvolvimento de projetos educativos.

O diferencial que pode ser analisado sob o prisma Brasileiro em relação à experiência educativa da Itália é o engajamento em massa expresso pelos movimentos educativos sociais, consolidados na parceria entre escola e família. Essa ativa participação social deve ser construída tanto pela escola quanto pelas políticas públicas, em busca de uma mudança paradigmática acerca da visão de todo país sobre a educação. Em Reggio Emilia, por exemplo, os regimentos se baseiam em três pilares: A Educação como um bem comum; A Educação como um direito; e A Educação como responsabilidade da comunidade, da sociedade civil e dos governos, sem que haja hierarquia quanto ao menor ou maior compromisso assumido em cada uma destas esferas.

Abordar o RCNEI obrigatoriamente remete a uma política instituída no período em que o Brasil vivenciava o neoliberalismo de modo fugaz. Por outro lado, há de se perceber que a Constituição Federal de 1988 e a Lei de Diretrizes e Bases da Educação Nacional - LDB 9394/96, ao reconhecerem o acesso da criança à Educação Infantil em creches e pré-escolas chamam atenção para estes sujeitos de direito, contrariando o pensamento vigente da época que via a criança como objeto de tutela. Para Fullgraf (2001, p.40), "o princípio da descentralização está atrelado a uma visão reducionista do papel do Estado em relação às políticas públicas, comprometendo a consolidação do atendimento educacional de qualidade às crianças pequenas". Essa reflexão acerca da política pública e da prática docente necessita ser constante entre os educadores não só na Educação Infantil.

Continuamente autores abordam a Educação como processo a ser ressignificado pelo caráter superficial com relação à formação integral do sujeito. Aos educadores mais um desafio, o de consolidar a função formativa e educativa da escola na contramão dos esvaziamentos. 
O que se pode denominar ideologia neoliberal compreende uma concepção de homem (considerado atomisticamente como possessivo, competitivo e calculista), uma concepção de sociedade (tomada como um agregado fortuito, meio de o indivíduo realizar seus propósitos privados) fundada na ideia da natural e necessária desigualdade entre os homens e uma noção rasteira da liberdade (vista como função da liberdade de mercado).(NETTO; BRAZ,2007, p.226).

Afirmar que ressignificar a Educação e fomentar a participação familiar na escola são desafios dos educadores pode soar como uma proposta neoliberal se não estiver atrelada ao engajamento social das Associações Comunidade-Escola e Conselhos Escolares, havendo a necessária e fundamental cobrança do Estado em tudo que lhe é legalmente obrigatório. A Educação percebida como processo formativo deve vincular-se à construção crítica dos saberes desde a Educação Infantil, de forma que a função social se cumpra, perpetuando o caráter histórico da produção desses saberes.

Para que isso não se perca, para que a humanidade não tenha que reinventar tudo a cada nova geração, fato que a condenaria a permanecer na mais primitiva situação, é preciso que o saber esteja permanentemente sendo passado para as gerações subsequentes. Essa mediação é realizada pela educação, entendida como a apropriação do saber historicamente produzido. Disso decorre a centralidade da educação enquanto condição imprescindível da própria realização histórica do homem. (PARO, 1997, p. 108).

Logo, a Educação Infantil, quando desvinculada da Assistência Social e proposta como processo intrínseco de Educar e Cuidar, assumiu todos os dilemas e desafios da Educação Básica, propondo-se à construção crítica dos saberes. Um debate interessante a todo educador se remete à reflexão sobre o financiamento e a formação dos professores desse nível de ensino, sendo fundamental a compreensão histórica para o entendimento acerca dos atuais desafios de fortalecimento das práticas pedagógicas na faixa etária de 0 a 6 anos.

A Lei nº12.796, embora de 2013, ganha corpo em 2016 no cenário educacional, evidenciando a necessidade de constante reflexão dos educadores sobre o papel destes sujeitos na Educação Infantil. Para Oliveira (2005), refletir sobre a Educação Infantil exige considerar os avanços legais que levam tempo para inferir mudanças no campo das crenças, das expectativas e dos valores.

A escolarização obrigatória para as crianças a partir de 4 anos não pode ser uma proposta de amadurecimento formal antes da hora, pois a ludicidade, o jogo, o brinquedo e a brincadeira sempre farão parte do universo infantil e precisam ser o foco de toda ação pedagógica. Vale ressaltar que o atendimento nas creches, de 0 a 3 anos, deve ser pensado a partir do contexto da inserção das mães no mercado de trabalho, sendo também valorizado 
como processo educativo com alto potencial formador em âmbito social, físico, cognitivo, afetivo e psicológico das crianças, deixando evidente a relação intrínseca entre o Cuidar e o Educar.

Acerca desta função essencialmente formativa da escola, Saviani (2005) corrobora ao analisar o trabalho educativo, como sendo o "ato de produzir direta e intencionalmente, em cada indivíduo singular, a humanidade que é produzida histórica e coletivamente pelo conjunto dos homens" (SAVIANI, 2005, p. 13).

A valorização de tais singularidades para que haja a necessária atenção à coletividade na construção do conhecimento exige a consciente mediação do professor desde a Educação Infantil, e tal mediação clama pelo conhecimento docente e pedagógico acerca das fases do desenvolvimento infantil e a importância da interação social. Acerca do processo de mediação no desenvolvimento das múltiplas linguagens da criança, Vygotsky (1998) é o fundamento epistemológico para muitas concepções pedagógicas atuais, sendo a infância uma condição social.

O conjunto de experiências vividas por elas em diferentes lugares históricos, geográficos e sociais, é muito mais do que uma representação dos adultos sobre esta fase da vida. É preciso conhecer as representações de infância e considerar as crianças concretas, localizá-las nas relações sociais, etc, reconhecê-las como produtoras da história. (KUHLMANN JR, 2001, p.31).

E esta condição social é valorizada nos preceitos da Pedagogia da Escuta, ou, Pedagogia dos Sentidos como aparece em muitas traduções, proposta que expressa a experiência educativa da cidade de Reggio Emilia, na Itália, onde Loris Malaguzzi estrutura sua obra em grandes Eixos, como Ética, Estética e Política. Tal concepção pedagógica tem como foco as relações que se estabelecem entre a criança e os saberes, nos tempos e espaços, pelo reconhecimento da escuta, da observação e da atenção como elementos fundamentais ao processo. Destarte, o professor é o mediador e interlocutor, criando situações de aprendizagem em que os sujeitos se posicionem ativamente, por meio de metodologias que estimulem a investigação, as experiências e as descobertas. A palavra-chave que remete à criança enquanto protagonista nessa proposta é a curiosidade. Hawkins (apud EDWARDS, 1999, p.55) assevera que, "um professor tem um papel único... Este não é o papel de uma mãe ou de um terapeuta ou de um colega, mas de alguém que valoriza os aprendizes e a aprendizagem profissionalmente". 
Esta função social da escola, que se propõe a incentivar a pesquisa como forma de interpretação do mundo encontra espaço na atualidade, sem a concepção de modelos a serem copiados por educadores, mas como experiências de desenvolvimento da autonomia, criticidade e criatividade. Uma proposta que se vincula à realização dos projetos pedagógicos, que nas primeiras décadas do século XX já se propagava com o filósofo John Dewey (1959), afirmando ser a Educação um campo de reconstrução das experiências.

A existência humana envolve impulsos dispersos para um projeto crescentemente unificado ou integrado; ou melhor, para uma série de projetos coordenados ou ligados entre si por interesses, aspirações e ideais de significados permanentes. Preparar para a vida será pôr a criança em condições de projetar, de procurar meios de realização para seus próprios empreendimentos e de realizá-los verificando pela própria experiência o valor das concepções que esteja utilizando. (DEWEY, 1959, p. 53).

Quando o protagonismo estiver efetivamente presente entre os objetivos da Educação Infantil, o ingresso no Ensino Fundamental poderá ocorrer de maneira menos fragmentada. Uma postura ativa auxilia a criança nas tomadas de decisões em atividades cotidianas, evitando o alerta anunciado por Tonucci (1986), quando afirma que as crianças produzirão muito, mas de maneira estéril. Assertiva que necessita ecoar na mente dos educadores para que os processos não sejam esvaziados, parciais e fragmentados.

Para haver aprendizagem, é preciso organizar um currículo que seja significativo para as crianças e também para os professores. Um currículo não pode ser a repetição contínua de conteúdos, como uma ladainha que se repete infindavelmente no mesmo ritmo, no mesmo tom, não importando quem ouça, quem observe ou o que se aprende. Afinal, sabe-se que o conhecimento não é verdade imutável, mas algo transitório, inacabado, imperfeito e em contínua pesquisa. (BARBOSA, 2008, p. 35).

O olhar pedagógico, que valoriza a observação, a escuta, os anseios e expressões das crianças, certamente relaciona-se à projetualidade na escola, expressa na significativa articulação da proposta pedagógica e a organização do ensino/aprendizagem em projetos, sem modelos a serem seguidos, mas caminhos a serem trilhados pela parceria que precisa existir entre aprendizes e mestres, que concomitantemente aprendem e reconstroem seus conceitos.

[...] o que a faz ser escola, instituição por excelência da cultura e da formação humana, são as questões que ela põe, a dúvida e a busca do saber como realidade viva, apaixonante e provocante da inteligência de docentes e discentes; é a relação que os envolve, em posições diferentes, no convívio com as ideias, os conceitos, os argumentos, as formas de apreensão e expressão do real; vértices do ensino, da formação e iniciação - de crianças, jovens e adultos, em níveis sempre mais elevados - ao saber, à autonomia e à liberdade, confirmando a existência e os ideais da humanidade, da vida coletiva e do bem comum. (COÊLHO, 2009, p. 181). 
Nesta relação dialética, professores e equipe pedagógica, durante toda a Educação Infantil, necessitam envolver os sujeitos da aprendizagem e seus responsáveis em todos os processos aquisitivos, de modo que a concepção da Educação enquanto formativa esteja viva e presente. Os encaminhamentos necessários à família e à criança frente à ida para o Ensino Fundamental se tornam mais eficazes quando durante o processo efetivou-se a real parceria. A visão pedagógica da equipe escolar necessita ser compartilhada de maneira contínua com todos os envolvidos com a escolarização.

\section{ANÁLISE DE DADOS}

As bibliografias aludidas corroboram com as vivências observadas in loco na cidade de Reggio Emilia, na Itália, onde por quatro dias crianças e educadores de maneira muito entrosada relataram e demonstraram experiências pedagógicas a partir da concepção pedagógica de Loris Malaguzzi, a Pedagogia dos Sentidos ou Pedagogia da Escuta. Um sentimento patriota muito latente foi visível em todas as falas, evidenciando o engajamento social que deu origem à proposta, pois, após o término da Segunda Guerra, de acordo com a história da cidade, mulheres ergueram e administraram escolas para seus filhos. Tal fato histórico dialoga com a realidade de Reggio, que mesmo sem financiamento previsto em Lei para Educação Infantil, suscitou na sociedade o necessário comprometimento que viabiliza a cobrança quanto aos investimentos do Estado. O breve relato se apresenta no intuito de que através da socialização da experiência, educadores do Brasil reflitam sobre possibilidades pedagógicas que fortaleçam a cidadania junto às crianças desde a mais tenra idade.

\section{DIÁRIO DE BORDO}

"Uma proposta de Educação criativa há cinquenta anos possibilitou reflexos na economia e cultura do município de Reggio Emilia."

Iuna Sassi, Secretária de Educação, Reggio Emilia, Itália, março de 2014.

Dia 1: 31 de março de 2014

Local: Centro Internacional Loris Malaguzzi - Sala Kuwait 
Atividade: Abertura e saudações de boas-vindas/Representação da RedSOLARE Brasil / Introdução ao programa do Grupo de Estudos Reggio Children / Palestra: O Projeto educativo das escolas e creches para a infância do Município de Reggio Emilia/Introdução e visita ao Centro Internacional Loris Malaguzzi/ Visita à Creche Rodari.

Figura 1.: Apresentação do Projeto Educativo de Reggio Emilia

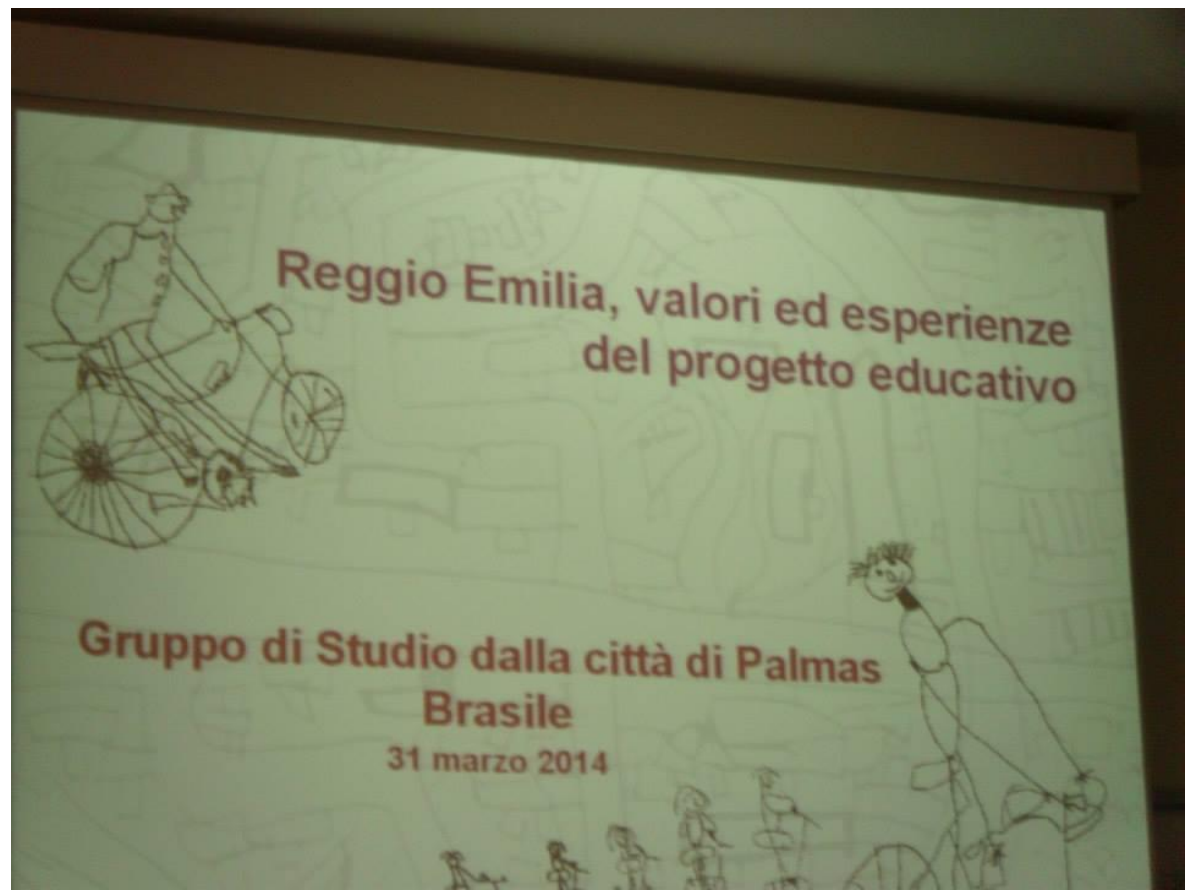

Fonte: Acervo pessoal da autora.

A abertura do evento se deu no Centro Internacional Loris Malaguzzi, iniciou com as boas-vindas e apresentação dos representantes da RedSOLARE Brasil/Itália. Para introdução ao Programa do Grupo de Estudos Reggio Children, foi destacado o projeto educativo das escolas e creches para a infância no Município de Reggio Emilia pelas pedagogistas (termo local) Paola Strozzi e Angela Barozzi, que enfatizaram a escola como espaço que acolhe, dialoga, compara e confronta, seguindo um percurso de práticas vivenciadas a partir da experiência da criança com o meio, o contexto, sua história, autonomia para construir e criar uma educação diferenciada que é compartilhada não só com as famílias e com a sociedade deste município, sendo um referencial em toda Itália e outros países.

A missão desses educadores é aprimorar um programa de percurso educacional para Reggio Emilia que valorize sua história, pois, não é possível entender a educação local sem entender sua cultura, suas origens, seus valores humanos, sociais, éticos e políticos. Nessa 
abordagem são mostrados efeitos pós-guerra que influenciaram sobremaneira a educação e o município. Porém, isso não desestimulou as famílias que se uniram em mutirão para construção da primeira escola para infância, XXV APRILE (25 de abril), no ano de 1945.

O educador italiano Loris Malaguzzi estabeleceu as diretrizes pedagógicas do projeto, o qual denominou Pedagogia da Escuta. Nesta perspectiva a criança é protagonista de seu processo de conhecimento. As pedagogistas foram unânimes ao afirmar que a ideia principal se relaciona a ouvir a si mesmo e aos outros, sem subestimar o potencial de cada criança, por menor que seja, percebendo que cada sujeito possui formas diferenciadas de pensar, agir e se expressar.

A Pedagogia da Escuta parte de fundamentos teóricos que referenciam Jean Piaget (1896-1980), John Dewey (1859-1952), e Lev Vygotsky (1896-1934), e pela cidade foi possível presenciar que a proposta pedagógica valoriza a linguagem gráfica, havendo exposições de trabalhos artísticos, produzidos pelas crianças, para a comunidade. Um elemento que também chama a atenção nas salas de aula é o fato de os materiais serem reciclados, não existindo brinquedos ou jogos pré-fabricados, os educadores utilizam os elementos da natureza de forma didática, folhas, flores, sementes, galhos, entre outros, geralmente disponíveis no próprio pátio das escolas. O grafismo está presente de maneira significativa em todas as atividades cotidianas.

No primeiro dia de visita foi observada uma turma de crianças com três (3) e quatro (4) anos, que na ocasião encontravam-se subdivididas em pequenos grupos de trabalho, andando com muita desenvoltura na sala de aula que dispunha de ambientes diferenciados, inclusive com degraus e obstáculos. A organização da sala de aula se assemelha a um atelier e é possível perceber a curiosidade das crianças na exploração dos vários materiais que naquele dia compunham o que no Brasil chamamos de Cantinhos. A educadora explica que na semana estavam estudando sobre as folhas, trabalhando conceitos a partir da fala das próprias crianças que identificam a diversidade nas texturas, tamanhos, cores, formatos.

Registros históricos do Centro Internacional Loris Malaguzzi, onde acontecem diversos cursos de formação continuada e projetos das escolas, relatam que até 1967, o município e o estado queriam abrir escolas públicas, mas inexistiam leis específicas. Um avanço significativo foi registrado em 1970, com movimentos comunitários em prol da 
infância, tendo como expoente o jovem pedagogo Loris Malaguzzi, que revolucionou a educação desse município.

Com a proposta de construção de uma educação de qualidade com um olhar para fora dos muros da escola, o educador criou o primeiro projeto denominado OLHO, cujo objetivo era levar as crianças para olharem a cidade, estabelecendo relações das vivências pessoais e coletivas com os espaços físicos.

Um aspecto curioso é o fato de crianças e familiares percorrerem as ruas de bicicleta e durante a ida para o Centro Internacional foi observado um grupo de pais, com o auxílio da Guarda Municipal, conduzindo-as até a escola. Após, foram coletadas informações de que os pais se revezam no acompanhamento deste percurso. Ao questionar uma pedagogista sobre os motivos para tal ação, ela elencou como prioridade a consciência ambiental sobre a necessidade de um modo de vida sustentável. Na sequência asseverou que em práticas coletivas as crianças podem se autorregrar, sem imposições dos adultos, de forma que percebam suas responsabilidades e potencialidades.

Na perspectiva deste Projeto Educativo, todos são importantes no convívio, as crianças respeitam e atendem aos adultos, os quais, segundo as pedagogistas do Centro, estão sempre atentos aos materiais. Existe um senso de pertencimento muito expressivo nas relações sociais, com o meio, com a natureza e os objetos, com o patrimônio público, com as produções infantis dentro e fora das escolas.

Sobre as atividades diárias, as pedagogistas relataram não haver uma rotina prédefinida, mas uma construção coletiva em pequenos ou grandes grupos, de como organizar as ações do dia e dar continuidade ao dia anterior, de acordo com a escolha da criança e conforme o seu desejo. Essa escolha é feita em assembleia, permitindo a esta construir seu próprio conhecimento de forma interdisciplinar e multidisciplinar, onde observa, faz leituras, escuta, projeta, troca ideias, dialoga, contrapõe, comunica e tem liberdade para aprender. Assim, foi observado que os espaços educativos estimulam a afetividade, o respeito, a valorização da individualidade e do grupo, a liberdade de escolha e a comunicação. E que durante as aulas a criança é provocada a buscar as várias respostas para suas perguntas.

Durante as palestras ficou evidente que o currículo privilegia as partes, adultos e crianças, possibilitando construções e conexões o tempo todo, sendo primordial não separar o 
tempo da criança como rotina escolar: hora do conto, do banho, da refeição, da brincadeira etc. Essa continuidade o professor tem na mente.

Neste momento foi oportuno estabelecer uma relação com a Educação Infantil no Brasil, sem o mérito de comparações acerca do que é adequado ou inadequado, mas em termos de diferenças culturais e organizacionais. No Brasil os Referenciais preveem o estabelecimento das rotinas, primando pela apresentação visual das mesmas às crianças, de forma que se localizem temporalmente ao longo do dia.

Em Reggio o currículo está sendo construído, a partir do estudo de vários documentos já elaborados. A Educação Primária segue as Indicações Nacionais, um tipo de Referencial Teórico, como um instrumento que se abre a várias questões e abordagens pedagógicas, exigindo do professor uma postura investigativa.

$\mathrm{Na}$ visita ao Centro Internacional Loris Malaguzzi, foram observadas as produções científicas das crianças das diversas Escolas e Creches do município, vivenciadas durante a prática na Creche RODARI, a qual apresentava espaços amplos, contextos diferenciados que possibilitavam às crianças a criação e o desenvolvimento educativo.

Dia 2: 01 de abril de 2014

Local: Escola do Centro Internacional Loris Malaguzzi

Atividade: Compartilhar de comentários, reflexões, observações sobre a visita à Escolal Palestra no Centro Internacional Loris Malaguzzi - Sala Kuwait com o tema: Reggio Emilia como sociedade que educa. Ética de Cidadania e Participação - Angela Barozzil Visita ao Centro de Reciclagem Criativa Remida/ Visita à Escola para Infância Villetta

No segundo dia de trabalho, o grupo de estudos visitou a escola no Centro Internacional Loris Malaguzzi, inaugurado em 2006, no intuito de conhecer as vivências e construções cognitivas das crianças em suas relações com os adultos e com o conhecimento de mundo. A priori foi destacado que o município investiu muito para dar continuidade ao Projeto Educacional, e que em 2008 os pedagogistas avaliaram que seria importante modificar a arquitetura dos prédios para atender três sessões da Educação Infantil e duas da Escola Primária, um só Projeto que foi ampliado posteriormente para mais três, tendo o atendimento por 3 anos na Educação Infantil e 5 anos na Escola de Infância. No ano de 2014, eram atendidos nessa escola, oito grupos totalizando 190 crianças em período integral e vinte e 
cinco pessoas trabalhando, sendo três tipos de contrato de trabalho: alguns são de responsabilidades do município (infância), do estado (primária), e cooperativas (prestadores de serviços).

O projeto pedagógico de Reggio Emilia é unitário, mas possibilita a cada escola dar sua subjetividade e o melhor de si para continuidade desta abordagem baseada nas ideias de Malaguzzi e na participação efetiva dos pais. Para iniciar as atividades diárias, não há uma rotina pré-definida, mas uma construção coletiva, em pequenos ou grandes grupos, à escolha da criança conforme o seu desejo, em sequência aos trabalhos mediados anteriormente. Vários espaços proporcionando a pesquisa e trabalhos em grupos. A criança é orientada a fazer outras atividades, principalmente manuais, utilizando muito material de sucata, valorizando a natureza.

Outro fator diferencial da abordagem pedagógica é a forma como mediam a aprendizagem a partir de recursos naturais como recursos pedagógicos, não adotam o livro didático sob a alegação de não condicionar o professor e a criança em suas construções mentais. Como cita Malaguzzi, cada professor deve construir seu próprio traço, dando sentido de pertencimento, priorizando a participação na construção da história educativa.

A avaliação apoia-se na construção do currículo, na "projetação" ou planejamento, acontece de forma contínua, contextual no percurso feito em três momentos: com as crianças (auto avaliação e de grupo); com os pais que vão à escola mensalmente observar o que as crianças estão fazendo e a cada dois meses em assembleia, com a participação dos professores que avaliam, escutam e refletem sobre a prática, os avanços ou pontos a serem melhorados.

O interessante é que as crianças constroem juntas o que irão avaliar (se esse ou aquele ponto, qual ou quais os critérios que serão utilizados); esses documentos produzidos são repassados aos pais mensalmente; assim como no Brasil, não existem testes e provas na Educação Infantil. Na indicação curricular há disciplinas de estudo e as competências a serem construídas, mas não há o conteúdo pré-determinado por sessões, ou série.

Na escola Reggiana, o erro não é algo a ser julgado, é algo que esquematiza, é um grande instrumento de interpretação. $\mathrm{O}$ erro não avalia a criança, mas o modo de trabalhar do adulto. É fruto da lógica e dos vários posicionamentos das crianças. Por isso, a partir do erro, 
o trabalho deve possibilitar condições para que os pequenos falem, debatam e assim, construam conceitos e teorias.

Assim como no Brasil, não há reprovação escolar na Educação Infantil, a apropriação da escrita e da leitura é um percurso da creche à educação primária. Trata-se de uma fase muito mais importante, não se acelera esse processo de zero a seis anos, os jogos e brincadeiras são espontâneos e permitem as formulações de cada criança. Uma sessão ou série não precisa corresponder à expectativa da que vem depois, cada escola tem sua própria característica, sua identidade, essas expectativas simplificam a escola no sentido de fortalecer a essência lúdica.

Na palestra "Reggio Emilia como sociedade que educa", Angela Barozzi abordou que ética de cidadania envolve a participação da sociedade, e esta é representada através do Conselho Infância Cidade, que envolve os pais, eleitos a cada 3 anos, não havendo nenhum critério excludente para participarem do processo, todos são estimulados à efetividade e ao compromisso para com a Educação, e mesmo com a saída da criança da escola os pais continuam fazendo parte do Conselho.

No período da tarde seguiu-se ao Centro de Reciclagem Criativa Remida, uma parceria entre o município, empresários e escolas que buscam a preservação do meio ambiente. A visita foi direcionada por funcionária do local que explanou sobre a importância deste trabalho, tanto para a cidade como para todos os envolvidos no processo, falou sobre como o material é trazido até o galpão e tratado de forma bem cuidadosa para ser disponibilizado à comunidade escolar, tanto para os professores como para os alunos que podem ter acesso a todo material através da carteira confeccionada no início de cada ano letivo. A partir das observações percebeu-se a importância dada à natureza, ao meio ambiente por toda a comunidade local, através da reciclagem do material e utilização nas unidades escolares (latas, tampinhas de garrafa, arame, copo, vidro, tubo de linha e outros).

Toda essa abordagem acerca do Projeto Pedagógico Reggiano foi demonstrada na prática durante as visitas. E no Centro de Reciclagem Criativa Remida foi observado o aproveitamento pelas escolas dos materiais de sucata através de Cooperativas, como também a realização de Oficinas para conscientização da comunidade no exercício da cidadania. 
Na sequência, a visita à Escola para Infância de Villetta, chamou a atenção para o espaço arquitetônico e a continuidade do processo educativo. Todos os espaços, desde o jardim até o sótão, são ambientes temáticos e dispostos de forma organizada, favorecendo o envolvimento e aprendizagem dos alunos e todos os trabalhos produzidos ficam expostos, para que os mesmos possam perceber seu processo de aprendizagem.

Dia 3: 02 de abril de 2014

Local: Escola no Centro Internacional Loris Malaguzzi

Atividade: Diálogo com a Secretária de Educação de Reggio Emilia - Luna Sassi / Workshop - Entre escolas e a cidade: Projetos e experiências das escolas e visibilidade nos eventos da cidade - Apresentação do Projeto realizado pela professora Paola Barchi - "As portas dos desejos" / Encontros com o território - Proposta cultural com voluntários da Fundação Reggio Children - Centro Internacional Loris Malaguzzi

Em sua abordagem, a Secretária de Educação do Município de Reggio Emilia, Sra. Iuna Sassi, destacou que a cidade tem por volta de 173 mil habitantes, crianças de $0-6$ anos representam $6 \%$ dessa população, desta porcentagem $65,8 \%$ frequentam as escolas públicas totalizando 6.630 alunos. São chamadas Creches Escolas que abrigam crianças de 0 a 3 anos ("é como serviço social") e Escola da Infância, crianças de 4 a 6 anos. Para acolher a todos, a cidade possui 12 Creches e 21 Escolas da Infância, que respondem bem à demanda. Internamente as diferentes faixas etárias são divididas por seção segundo a Secretária.

São assim divididas, 3-6 anos (Infância), 6-11 anos (primária), 11-14 anos (1 ${ }^{\circ}$ grau) e 14-19 anos ( $2^{\circ} \mathrm{Grau} /$ Institutos Técnicos e Institutos Profissionais), 20 anos seguem para as Universidades.

Referenciou as Escolas da Infância sendo 58\% Estaduais, 28\% privadas ligadas à Igreja Católica, 12\% Municipal e 2\% outros tipos de convênios. Acerca do Plano Escolástico, os professores trabalham 40h (Infância), 27h (primária), 30h ( $\left.1^{\circ} \mathrm{Grau}\right)$ e $28-30 \mathrm{~h}\left(2^{\circ} \mathrm{grau}\right), 40 \mathrm{~h}$ (Institutos Profissionais).

Pontos fortes: integração escolar dos estudantes com os estados, momentos de formação para os docentes, as refeições são pagas pelos pais em três níveis: $1^{\circ}$ - Classe alta paga $100 \%$, Classe média - 50\% e a Classe carente, que são poucos, são mantidas pelo município; as crianças em conjunto com os pais fazem ações para a escola/comunidade; os 
laboratórios são conduzidos por educadores para fortalecer o aprendizado da Língua, principalmente por imigrantes; a escola de tempo integral está sendo objeto de investigação por Reggio Emilia pela pouca procura. A Secretária explanou de modo positivo acerca da acolhida a estrangeiros.

Destacou que a experiência de Reggio Emilia é a melhor do mundo porque já nasceu com outras experiências, estabelecendo relações estreitas com Universidades Americanas, Espanholas, Inglesas e com grandes figuras como Jerome Bruner, psicólogo estadunidense, pioneiro nos estudos de Psicologia Cognitiva.

Foram destacados vários projetos, dentre eles "As portas dos desejos" que enfoca a criatividade da criança em expor suas hipóteses, e a partir dessa temática, o Projeto vai fluindo e desencadeando o aprendizado. As crianças vão construindo de forma bidimensional e tridimensional suas experiências, utilizando materiais como argila e reciclados.

Durante a visita "Encontros com o território - Proposta cultural com voluntários da Fundação Reggio Children” percebeu-se a consonância entre a cultura, a história e a educação demonstradas a partir das construções nos Museus.

Dia 4: 03 de abril de 2014

Local: Visita técnica ao Ateliê das Águas e Energias De Onda em Onda Atividade: Visita e oficina no Campo Base do Ateliê De Onda em Onda

Figura 2.: Ateliê De Onda em Onda realiza oficinas com a comunidade e escolas acerca do uso sustentável da água.

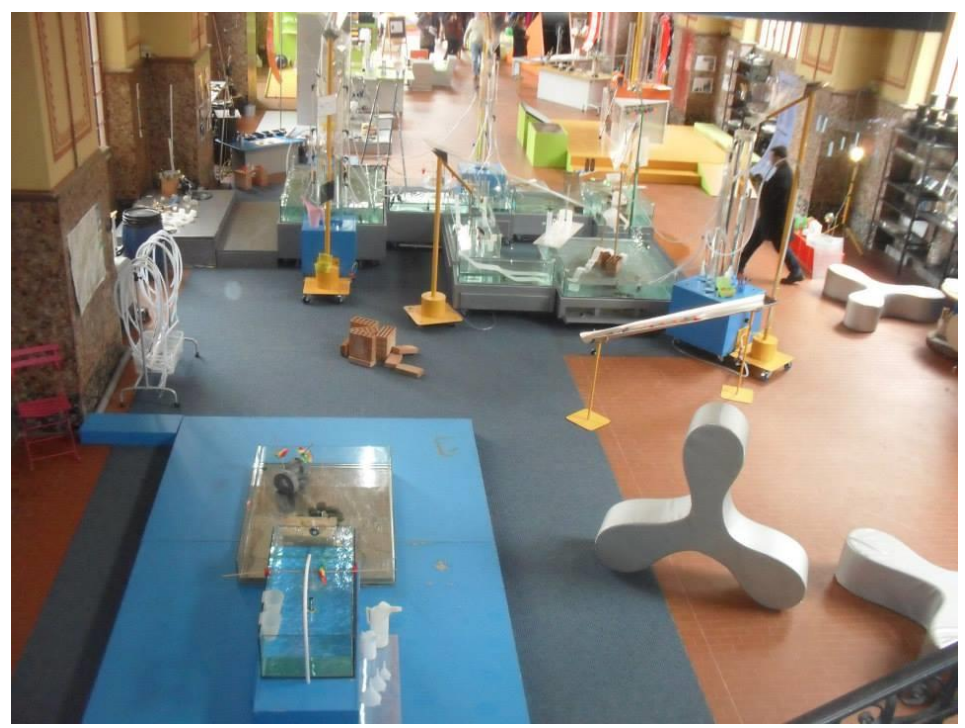

Fonte: Acervo pessoal da autora. 
Um lugar que permite a exploração dos fenômenos físicos relacionados aos recursos água e energia. Situa-se em Liconchio, o maior município da província de Reggio Emilia, dentro do Parque Nacional Apenino Tosco-Emiliano.

Este projeto propõe uma abordagem científica sendo um convite para as crianças, adolescentes e adultos olharem as coisas de uma maneira incomum, despertando sua curiosidade, levando-os a questionamentos que, aparentemente, não poderiam ser explicados sem uma investigação, tentativas de construção de hipóteses e teorias, possíveis através da experimentação. A todo instante um questionamento é realizado pela guia no intuito de fomentar hipóteses acerca das estruturas e suas relações com a água.

O Atelier De Onda em Onda, de acordo com as guias, foi idealizado como um ser que possui alma, onde a mente e as mãos, a racionalidade e a imaginação, trabalhando em conjunto, se entrelaçam e se completam, gerando novos conhecimentos sobre o mundo.

No Atelier é possível observar a natureza, explorar e refletir sobre seus potenciais, principalmente na observação da Usina Hidrelétrica de Ligonchio.O projeto é promovido pelo Parque Nacional Apenino Tosco-Emiliano, em colaboração com o Município de Ligonchio, Enel e com a consultoria do Reggio Children.

O envolvimento dos professores em todas as diferentes fases do projeto é essencial: os adolescentes recebem uma preparação prévia, discutindo temas de interesse, elaborando perguntas, e o trabalho prossegue posteriormente, na própria escola.

As experiências iniciadas no Atelier sugerem futuros projetos, desenvolvidos na escola, onde os educadores promovem reflexões para um retorno ao Atelier. Os vários elementos internos do Atelier dialogam com a natureza exuberante do macro projeto da Estação Hidrelétrica e seu entorno.

\section{CONSIDERAÇÕES FINAIS}

A primeira infância quando compreendida como fase potencialmente criativa e autônoma possibilita uma concepção pedagógica que privilegie o diálogo, a descoberta, a exploração e a manifestação dos sentidos, principalmente a escuta, a observação e a atenção. 
Educadores e educandos se relacionam em prol da construção coletiva do conhecimento, sem que este se apresente como inerte ou absoluto. Esta visão propõe um constante desafio para todos os sujeitos educativos. Professores e alunos investigadores e parceiros frente ao ensino e a aprendizagem, processos intrínsecos, indissociáveis.

Refletir sobre a Pedagogia da Escuta que tem como ícone Loris Malaguzzi se apresenta como uma possibilidade de atuação, sem que se caracterize como um modelo a ser reproduzido, muito menos a partir de uma visão romanceada sobre Reggio Emilia e seus encantos naturais, mas como ações pedagógicas concretas e reais que levaram a cidade a patamares de excelência educacional, a partir do princípio de que à escola cabe a mediação para o desenvolvimento da autonomia.

A práxis do professor leva a criança a ser pesquisadora e também mediadora no processo em que é capaz, desenvolve habilidades e competências para perceber formas simples e complexas relacionadas às situações de sala de aula, com o diferencial da participação da comunidade escolar nos processos de tomada de decisões.

Situações de aprendizagem que explorem os sentidos e que estimulem as linguagens expressivas, cognitivas e comunicativas reforçam o trabalho coletivo, o senso de solidariedade e a escuta. As relações interpessoais independem do local em que professores e crianças estejam no universo, dependem das intenções pedagógicas às quais o projeto da escola se propõe. Antigos questionamentos sempre atuais que indagam sobre o porquê de educar, o para quê educar, para quem, sempre a partir da honesta reflexão que envolve os valores culturais de cada realidade educativa.

A pesquisa na escola encontra escopo nos projetos educacionais que contemplam os diversos contextos quando expressam anseios e vivências de educadores e educandos, que desde a mais tenra idade devem ser ouvidos a todo instante, uma educação para a autonomia que tem a curiosidade como mola propulsora, para que a partir de outras realidades educadores se desafiem continuamente em prol de uma experiência lúdica e significativa em suas salas de aula. 


\section{REFERÊNCIAS BIBLIOGRÁFICAS}

BARBOSA, Maria Carmem Silveira; HORN, Maria da Graça Sousa. Projetos Pedagógicos na Educação Infantil. Porto Alegre: Grupo A, 2008.

BRASIL. Ministério de Educação e do Desporto. Referencial Curricular Nacional para Educação Infantil. Brasília, DF: MEC, 1998.

COÊLHO, Ildeu Moreira. Educação, cultura e formação: o olhar da filosofia. Goiânia: Ed. PUC Goiás, 2009.

DEWEY, John. Vida e Educação. São Paulo: Melhoramentos, 1959.

FULlGRAF, Jodete Bayer Gomes. A infância de papel e o papel da infância. Florianópolis, 2001, 141 f. Dissertação (mestrado em Educação). Centro de Ciências da Educação, Universidade Federal de Santa Catarina.

HAWKINS, Frances Pockman. The logic of action. Young children at work. Boulder, CO: Associated University Press. In: EDWARDS, Carolyn (org.). As Cem Linguagens da Criança: a abordagem de Reggio Emilia na educação da primeira infância. Porto Alegre: Artes Médicas, 1999.

KUHLMANN JÚNIOR, Moysés. Infância e educação infantil: uma abordagem histórica. 2 ed. Porto Alegre: Mediação, 2001.

LAKATOS, Eva Maria. MARCONI, Marina de Andrade. Fundamentos de Metodologia Científica. 5 ed. São Paulo: Atlas, 2003.

MINAYO, Maria Cecília de Souza (org). Pesquisa Social: Teoria, Método e Criatividade. 14 ed. São Paulo: Vozes, 1992.

NETTO, José Paulo; BRAZ, Marcelo. Economia política: uma introdução crítica. São Paulo: Cortez, 2007.

OLIVEIRA, Stela Maris Lagos. A legislação e as políticas nacionais para a educação infantil: avanços, vazios e desvios. In: Machado, Maria Lucia de A.. Encontros e desencontros em educação infantil. 2 ed. São Paulo: Cortez, 2005.

PARO, Vitor Henrique. Gestão democrática da escola pública. São Paulo, Ática, 1997.

SAVIANI, Demerval. Pedagogia histórico-crítica: primeiras aproximações. Campinas: Autores Associados, 2005.

TONUCCI, Francesco. A los três anos se investiga. Barcelona: Hogar Del Libro, 1986.

VYGOTSKY, Leon. Semyonovich. A formação social da mente. 6 ed. São Paulo: Martins Fontes, 1998. 